\title{
Anne Chamayou, Alastair B. Duncan (a cura di), Le rire éuropéen
}

Dina Catenaro Catenaro

\section{(2) OpenEdition}

\section{Journals}

\section{Edizione digitale}

URL: http://journals.openedition.org/studifrancesi/6113

DOI: 10.4000/studifrancesi.6113

ISSN: 2421-5856

\section{Editore}

Rosenberg \& Sellier

\section{Edizione cartacea}

Data di pubblicazione: 1 mai 2011

Paginazione: 218-219

ISSN: 0039-2944

\section{Notizia bibliografica digitale}

Dina Catenaro Catenaro, «Anne Chamayou, Alastair B. Duncan (a cura di), Le rire éuropéen», Studi

Francesi [Online], 163 (LV | I) | 2011, online dal 30 novembre 2015, consultato il 13 janvier 2021. URL: http://journals.openedition.org/studifrancesi/6113; DOI: https://doi.org/10.4000/studifrancesi.6113

Questo documento è stato generato automaticamente il 13 janvier 2021.

\section{(c) (†) $\ominus$}

Studi Francesi è distribuita con Licenza Creative Commons Attribuzione - Non commerciale - Non opere derivate 4.0 Internazionale. 


\title{
Anne Chamayou, Alastair B. Duncan (a cura di), Le rire éuropéen
}

\author{
Dina Catenaro Catenaro
}

\section{NOTIZIA}

ANNE CHAMAyou, ALASTAIR B. DUNCAN (a cura di), Le rire éuropéen, Perpignan, Presses

Universitaires de Perpignan, «Collection Études», 2010, pp. 447.

1 Il volume raccoglie gli Atti del convegno organizzato dall'Università di Perpignan Via Domitia e dall'Università di Stirling svoltosi a Perpignan nell'ottobre 2007. Il tema dell'incontro mette in luce il crescente interesse che gli studiosi di varie discipline (letterati ma anche etnologi, sociologi, storici e socio-linguisti) hanno manifestato nei confronti del riso nelle sue molteplici sfaccettature: i fondamenti filosofici, le argomentazioni psicologiche e la funzione sociale sono soltanto alcuni degli aspetti di una forma espressiva che spesso diventa per un popolo strumento necessario per l'affermazione del proprio senso di appartenenza ad una comunità. In questa sede ci limiteremo ad analizzare i saggi che, nonostante il titolo, concernono le letterature extra-europee, nello specifico africane, nei loro rapporti con l'Europa, su cui si sono soffermati gli studiosi Alastair D. Duncan, David Murphy, Aedín Ní Loingsigh e Antoinette Tidjani Alou, analizzando in particolare la funzione svolta dal riso nei rapporti tra colonizzato e colonizzatore.

2 L'articolo di Alastair D. DUNCAN (caricatures de noirs dans la presse humoristique européenne: 1879 à 1958, pp. 329-347) che apre la sezione «Europe-Afrique (et retour)» (pp. 327-386) si concentra sulla rappresentazione caricaturale dei neri in Europa in epoca coloniale, in particolar modo dalla fine dell'Ottocento fino alla vigilia dell'indipendenza degli stati africani (fine anni Cinquanta). Attraverso l'analisi di riviste e giornali umoristici e satirici dell'epoca di area tedesca, belga, francese e inglese lo studioso ha evidenziato la persistenza di alcuni stereotipi tra i quali spicca l'immagine del Nero rappresentato come un essere selvaggio in grado di esercitare sul Bianco reazioni ambivalenti: il 
fascino dell'esotico e, contemporaneamente, la paura del diverso. Tale rappresentazione, afferma D. Duncan, ha conosciuto un'evoluzione nel corso del tempo, evoluzione dovuta al cambiamento delle ideologie da parte dei colonizzatori che sono andate man mano concentrandosi più sulla mission civilisatrice (p. 346) che sulla questione dell'inferiorità razziale. I caricaturisti sembrano quasi invitare gli spettatori europei a immaginare «le regard que poserait le noir sur le blanc» (p. 349). Ma, sottolinea lo studioso, la rappresentazione caricaturale continua ad operare e a discriminare: «La couleur reste la ligne de partage definitive» (p. 349).

3 L'intervento di David MURPHY e Aedín Ní LoINGSIGH (Something to Laugh About? Representations of Europe in Francophone African Cinema and Literature, 1954-1974, pp. 349-364) sposta l'attenzione sulla satira effettuata da alcuni cineasti e scrittori africani a spese dei colonizzatori: ciò che emerge dall'accurata analisi di testi e film che si collocano tra gli anni ' 50 e la fine degli anni ' 70 è il superamento degli stereotipi del passato $\mathrm{e}$, cosa ancor più rilevante, la volontà di trovare uno spazio comune nel quale gli Africani e gli Europei possano imparare a ridere l'uno dell'altro senza cadere nella trappola del gioco delle parti: attraverso l'accettazione di una storia condivisa, si può dare vita a un «shared laughter that signals greater awareness of oneself and others rather than the hysteria caused by a traumatic and painful past» (p. 364). Chiude la rassegna dedicata alla funzione svolta dal riso nei rapporti tra Africa ed Europa l'intervento di Antoinette TIDJANI ALOU (Le rire de l'africain en situation coloniale chez Ma Inoussa dit «Dan Alalo» et Ferdinand Oyono, pp. 365-386) dedicato a due scrittori africani appartenenti ad aree geografiche differenti, Ma Azou Inoussa alias Dan Alalo e Ferdinand Oyono, che hanno fatto del riso uno strumento di «démystification parodique» (p. 367) delle autorità e gerarchie sotto il regime coloniale. Attraverso un riso dalle sfumature complesse, il cantore popolare nigeriano (Dan Alalo) e lo scrittore camerunense (Ferdinand Oyono) hanno saputo effettuare una satira acuta che, pur puntando il dito contro i colonizzatori, non ha risparmiato gli stessi colonizzati. Il riso assume così una funzione catartica che permette la presa di distanza necessaria nei confronti di una storia, quella coloniale, che si pone oltre i limiti dell'immaginabile.

4 Ai lavori fin qui analizzati, che escono dall'area prettamente europea all'interno della quale si collocano gli articoli dei primi quattro capitoli, va riconosciuto il merito di aver esplorato un campo di ricerca, quello dell'humour e della satira in area coloniale e postcoloniale, in parte ancora sconosciuto. 